\title{
Refugees in Europe: national overviews from key countries with a special focus on child and adolescent mental health
}

\author{
Matthew Hodes ${ }^{1} \cdot$ Melisa Mendoza Vasquez ${ }^{2} \cdot$ Dimitris Anagnostopoulos $^{3} \cdot K_{\text {Kalliopi Triantafyllou }}{ }^{3}$. \\ Dalia Abdelhady ${ }^{4} \cdot K$ arin Weiss ${ }^{5} \cdot$ Roman Koposov $^{6} \cdot$ Fusun Cuhadaroglu $^{7} \cdot$ Johannes Hebebrand $^{8}$. \\ Norbert Skokauskas ${ }^{9}$
}

Published online: 21 December 2017

○) Springer-Verlag GmbH Germany, part of Springer Nature 2017

\begin{abstract}
Many European countries are becoming multicultural at a previously unseen rate. The number of immigrants including refugees has considerably increased since 2008, and especially after the beginning of the war in Syria. In 2015, 88,300 unaccompanied minors sought asylum in the Member States of the European Union (EU) and most came from Syria, Afghanistan, Iran, Iraq, Somalia and Eritrea. As a reaction to increased immigration, governments in many countries including Germany, Sweden and Norway implemented more restrictive immigration policy. A requirement for all countries, however, is the protection and welfare provision for all arriving children, regardless of their nationality, ensured by international and national legal frameworks. This paper provides an overview of the post 2015 immigration crisis in key European countries with a special focus on current demographics, refugee children, mental health studies, policies and practical support available for refugees.
\end{abstract}

This article is part of the focused issue 'Mental health issues in refugees'.

Norbert Skokauskas

norbert.skokauskas@ntnu.no

1 Centre for Psychiatry, Imperial College London, London, UK

2 International Organization for Migration Ankara, Ankara, Turkey

3 Department of Child and Adolescent Psychiatry, Medical School, National and Kapodistrian University of Athens, Athens, Greece

4 Lund University, Lund, Sweden

5 Former University of Applied Sciences Potsdam, Potsdam, Germany

6 UiT The Arctic University of Norway, Tromso, Norway

7 University of Ankara, Ankara, Turkey

8 University of Duisburg-Essen, University Hospital Essen, Essen, Germany

9 Centre for Child and Adolescent Mental Health and Child Protection, Institute of Psychiatry, Norwegian University of Science and Technology (NTNU), Klostergata 46, 7030 Trondheim, Norway

\section{Introduction}

Several countries in Europe and beyond have recently witnessed a large influx of refugees and immigrants. With the continuation of war, organized violence, and extreme economic hardship, many people are displaced and lured to more affluent countries in Europe and North America. The migration routes and dispersal policies in resettlement countries mean that asylum seekers may settle in both rural and urban communities, which struggle to meet the humanitarian demands.

Flight and immigration are by no means novel phenomena; the history of Europe abounds with waves of forced migration, which have more or less shaped the cultures of European countries. The ongoing influx is not completely different from previous ones. However, the current refugee crisis for the first time affects Europe as a political union in a globalized world. Furthermore, the current refugees and immigrants originate from Asian, African, and single European countries, entailing a substantial heterogeneity, which surpasses that of previous waves.

Immediate practical solutions are required to support basic needs for housing, financial support for food and clothing, and provision of medical care. As time elapses, other needs for language courses, schooling, training and employment emerge. The refugees and immigrants require legal 
services and information on cultural issues to help them to acculturate and settle in the host community. Cultural differences may spark tensions between the asylum seekers and the host population at an interpersonal level and even trigger outbreaks of violent attacks, the perpetrators being either individuals of the host population or the refugees/immigrants. On the other hand, contact between the population of the host communities and the refugees and immigrants can entail a mutually beneficial exchange, such enriched global awareness and multicultural peer contact in schools. As time goes on refugees', especially children's, mental health needs may become apparent and then access to appropriate services is required.

The idea for this overview arose from the international conference "Key elements of model communities for the successful integration of refugees and migrants-an interdisciplinary perspective" (http://www.inzentim.de/inzentim-kongress-2017/), which took place 21-22 June 2017 in Essen, Germany. In addition to historical overviews and a synopsis of the current situation in key European countries, symposia focused on legal aspects, facilitation of language acquisition, schooling, employment, medical services including those for mental health problems, radicalization, security and safety issues and the special needs of particular vulnerable subgroups including minors.

This editorial along with this special issue on the refugee crisis was also inspired by the commitment of the European Society of Child and Adolescent Psychiatry (ESCAP) (https://www.escap.eu/) and the editorial board of European Child + Adolescent Psychiatry to provide an international forum for mental health issues related to the uprooting of so many minors throughout the world. Two previous editorials $[1,2]$ underscore this commitment.

The current editorial provides an overview of the post 2015 immigration crises in key European countries, starting with countries that lay on the migration route, Turkey and Greece and moving on to consider resettlement countries Germany, UK, Sweden and Norway. There is special focus on current demographics, refugee children's mental health studies, policies and practical support available for refugees.

\section{Turkey}

The Republic of Turkey is a Eurasian country with 79.5 million inhabitants. Turkey adopted an open-door policy since the start of the Syrian War in 2010 to accept the entry and stay of Syrian citizens and others, mainly from Iraq and Afghanistan, who had to flee their country. The mass influx from Syria to Turkey began in 2011 and has since then increased substantially. As of October 2017, there were $3,451,383$ Syrians under temporary protection status (1,603,709 between 0 and 18 years). In 2016, 31,523 Iraqis and 21,445 Afghanis registered for international protection status. The Turkish State has not only passed Temporary Protection Regulation to legalize the status of Syrians in Turkey but also managed a massive humanitarian response. Today, with the acceptance of the fact that millions of Syrians will not return to their country even if the war ends, larger initiatives and policy making are being implemented to develop integration strategies, hand in hand with ongoing emergency measures.

Protection for all children, regardless of nationality, is ensured by the legal framework of Turkey's Child Protection Law. The Ministry of Family and Social Policies, in coordination with the Directorate General for Migration Management (DGMM), is responsible for provision of support to children in Turkey. The overarching aim is to pursue the best interests of the child. Refugee children in Turkey, both Syrians and those of other nationalities (Afghan, Iraqi, Iranian, Somali and others) have the right to primary and secondary education in Turkey free of charge and the government strongly encourages all families to enroll their children in schools even if they are waiting to be resettled to a third country. The Ministry of National Education is responsible for ensuring and managing refugees' access to education. Syrian children can register at Temporary Education Centers or Turkish national schools. People under other international protection status and applicants of international protection can enroll to Turkish schools only. It is widely believed that schooling helps to improve academic skills and knowledge but also eases the adaptation and inclusion process of societies into the host country.

The 2013 Law on Foreigners and International Protection no 6458 (LFIP) laid the foundation for a comprehensive migration management reform, establishing the Directorate General for Migration Management (DGMM) under the Ministry of Interior. Within the LFIP, there are three regulations; (1) regulation for the Implementation of the Law no 6458; (2) temporary Protection Regulation (2016), and Regulation on Combatting Human Trafficking and Protection of Victims (2016). The DGMM has been authorized to cooperate with and provide coordination to other public agencies and organizations, non-governmental organizations, local governments, universities, and international organizations with respect to the planning and performance of the activities related to harmonization. The Communication Center for Foreigners (YIMER 157) was established in August 2015 within the DGMM and it provides support and helpline in six languages (Turkish, English, Russian, Arabic, German, and Persian) around the clock every day of the week, from which migrants can receive information regarding such matters as visas, residence permits, international protection, temporary protection, etc.

The Ministry of Family and Social Policies (MFSP), municipalities, Red Crescent or NGOs have established 
community centers in the regions where refugees are highly populated to provide training and courses for refugees, deal with their problems and conduct harmonization-oriented programs. It is foreseen that these centers, which currently number around 60 in all of Turkey, would work under the directorate of the Red Crescent in the future. The number of such centers established at the initiative of the district municipalities in Istanbul has been rather limited. Many programs on language, education, health, informing, working life (finding a job) and also recreational courses are currently being carried out in Multi-Purpose Community Centers which have been established by Municipalities.

All registered refugees, especially including children, have the right to access medical care. Turkish authorities are responsible for the identification of unaccompanied and separated children and to provide necessary support and assistance. There are no data indicating the number of unaccompanied refugee children in Turkey. The United Nations High Commission for Refugees (UNHCR) supports the state by providing guidance to the authorities on identification and care arrangement. The MFSP has established 10 Child Support Centers for Refugees at different cities where the unaccompanied children are being taken care of and psychosocial services are provided. In places where there are no such established services, unaccompanied children are taken under the protection of the State and placed at the Child Care Homes of MFSP where they stay together with native children. The DGMM, MFSP and the Association of Ankara photographers (AFSAD, a platform of NGOs) are continuing their efforts to find the families of separated children to reconnect them with their families.

MFSP has established a committee, which includes the directors of the municipalities, academics and NGOS to find and follow up the children who are working or begging on the streets. Families of these children are being identified and also supported.

Special outpatient child psychiatry clinics for refugee children have been established in Istanbul as well as in other centers. Despite its establishment almost a year ago, the Istanbul outpatient unit received only about 30 referrals, mostly for anxiety disorders. There are some children with developmental disorders and only single cases with posttraumatic stress disorder (PTSD).

A number of reports have been published from Turkey since 2010 on refugee mental health. These address the prevalence of disorders in community samples. A study focused on 136 refugee children in a refugee camp in the southeast of Turkey, $70 \%$ of whom were younger than age $11 ; 61 \%$ were attending school and $70 \%$ were livings with their parents [3]. Using the K-SADS interview, PTSD was the most frequent diagnosis (43\%), followed by depression (28\%), nocturnal enuresis (10\%), anxiety disorders $(9.6 \%)$ and conduct disorders (5\%). All children with PTSD had witnessed either a gunfight or a bombing at their former home countries, and $76.7 \%$ of this group witnessed relatives or friends getting injured during war or migration. A high rate of psychiatric disorders was also found in the study of Yazidi refugee children [4]. Other reports describe clinical service and training initiatives $[5,6]$.

\section{Greece}

Greece is a cultural crossroads between East and West and a major entry point for refugees to the EU. Greece has had a long tradition of hospitality since antiquity and phenomena of racist violence have not been observed. During the last few years, efforts to introduce new legislation to address issues of migration and racism have intensified. Some cases of discrimination have surfaced because of the Greek economic crisis and in particular the dramatic increase in youth unemployment. Gross domestic product has fallen by $25 \%$ since 2010, the income and employment rate of both native residents and immigrants have decreased, and the public health sector and welfare sector have been affected by austerity measures [7]. During the years of the Greek economic crisis, an abrupt and steep increase in the numbers of immigrants occurred. Nevertheless, Greece has faced this challenge and has established laws for child protection, human rights, education and health care for immigrants and refugees.

During the greater part of the twentieth century, Greece was characterized by emigration, either to America in the beginning of the century or to Germany and Australia after the Second World War. Since 1988, Greece has been transformed into a host country for immigrants, accepting hundreds of thousands of economic immigrants coming mainly from the Balkans and East Europe. In particular, from 1988 to 2004, the number of economic immigrants living in Greece was more than 1,000,000 (total population in Greece approximately 10,000,000). From 2006 to 2014 , there was an increased influx of illegal immigrants (50,000-100,000 per year). During 2015, according to the Hellenic coast guard, there was an increased influx compared to previous years: 804,565 immigrants and refugees arrived in Greece. The majority of them were Syrian refugees $(N=457,149)$. The other main countries of origin were Afghanistan $(N=194,827)$, Iraq $(N=77,475)$, and Iran $(N=21.133)$ [8]. Most refugees (45\%) were men, 35\% were children, and $20 \%$ were women. According to the UN Refugee Agency during 2015, 860,000 refugees and migrants without travel documents have entered Greece by sea with the Greek islands becoming the main gateway to the European Union. More than 250 deaths and 149 missing people were recorded in Greek territorial waters in 2015. 
From 2013 to 2017, 33,677 child and adolescent refugees sought asylum in Greece: 24,541 children (0-13 years old; males $=12,849)$ and 9,136 adolescents (14-17 years old; males $=6915$ ). From 2013 to 2017, the total number of unaccompanied minors who sought asylum was 4669 $(0-17$ years old; males $=4170)$. It is noteworthy that statistics underestimate the actual numbers of child refugees who reach Greece with or without their own families, given that there may be a great difficulty in verifying the actual age of these minors [9]. Young refugees in Greece usually claim to be older or younger according to what is better for them to gain legal benefits. In September 2017, there were approximately 2850 unaccompanied children in Greece among which 1096 were accommodated in 50 unaccompanied child shelters and 240 in 8 safe zones nationwide [10]. According to a previous study which examined the psychopathology of children of the economic immigrant families during the period 1990-2000 in Greece, and their psychiatric service utilization, immigrant families were significantly worse off in economic terms, had lower status jobs, worse housing conditions and only a low rate of health insurance coverage. No differences between the immigrant children and their Greek peers were found regarding frequency or type of psychiatric diagnosis. Immigrant children did not present more serious or diverse psycho-pathology than did Greek children. However, $91 \%$ of the immigrant group received a psychosocial diagnosis as opposed to $49 \%$ of the Greek group. Immigrant families had equal levels of service utilization as Greek families. However, it was apparent that immigrant families did not seek for help as readily as their Greek counterparts [11].

A recent study examined the differences in psychopathology between economic immigrant, refugee and Greek families who were referred to the Department of Child and Adolescent Psychiatry, Agia Sophia Children's Hospital, Athens during 2005-2014. It was found that the proportion of child and adolescent refugees with a psychiatric diagnosis was lower than that of immigrants. Child and adolescent refugees had received fewer psychiatric diagnoses (according to ICD-10) than Greeks. On the other hand, refugees showed a greater number of factors influencing health status ( $Z$ codes in ICD-10) compared to Greeks, and the proportion of refugees who had at least two $\mathrm{Z}$ codes was greater than for both immigrants and Greeks. Refugees after 2010 sought for help mainly because of social factors and factors related to their health status. These results might suggest that refugee families seek help for reasons not directly related to mental health, which could reflect their different needs (i.e., pursuit of a stable living condition, access to food and of a future perspective) or their difficulty in obtaining access to public health services as compared to immigrants and natives [12].

Greece has incorporated all EU regulations and United Nations resolutions on refugee/migration flows. All youths upon entering Greece are under protection from the State that ensures all their human rights (social welfare, education, health). A national committee for the management of unaccompanied minors has been formed by the Greek authorities in order to ensure the protection and wellbeing of these children. Medical examinations and health care, psychosocial support, and housing are being offered free of charge by a network of public services and non-governmental organizations through the national child protection legislation. All the necessary means, such as internet and social media facilitating immigrants' access to the public health sector have been used.

The reception capacity for Greece established by the UNHCR and its partners, with EU funding, in support of the relocation scheme, reached the target of 20,000 accommodation places on 1st December 2016. The Hosting and Accommodation Programs, which were developed by UNHCR, the UN Refugee Agency and are funded by the European Union Civil Protection and Humanitarian Aid (ECHO), continue in 2017. The Greek government provides free of charge health services for refugees in the National Health System (NHS), and vaccinations that cover all the hot spots and hospitality centers.

During 2017, in collaboration with the Ministry of Education, Research and Religious Affairs, the Greek mission of International Organization for Migration (IOM) implemented an education program and supplied children with the necessary equipment (notebooks, pens, pencils and other school supplies). 2500 children have attended courses in Greece since the beginning of 2017. Nevertheless, a number of immigrants do not want to stay in Greece and plan to move to West Europe. This results in a prolonged uncertainty about their future. Moreover, many parents decide not to send their children to school, since they perceive that if they give their consent for their children to attend school, this will lead them to stay permanently in Greece.

\section{Germany}

Germany is a federal republic with 16 federal states. While the national legislation sets the frame for migration and integration, including the reception of refugees, there is quite a difference between the federal states not only regarding their general attitudes towards the reception of refugees, but also regarding the reception system itself. Additionally, the states differ also in their general educational systems or economic power. Migration to Germany has already a long history and attitudes towards integration differ between the states, and especially between the former East and Western part of Germany.

The right for asylum is a basic individual right, anchored and defined in the German constitution. The German federal 
system for the reception of refugees involves three different levels: the federal government is responsible for the principal decision to accept refugees and the national legislation. All asylum seekers are allocated to the 16 states of Germany and to communities according to a certain key, taking population size and economic power into account.

The number of refugees began increasing already in 2008. By 2010 the Federal Office for Migration and Refugees (BAMF) was no longer able to cope with the mounting numbers of refugees, and decisions for granting asylum took longer and longer. When the numbers increased tremendously in 2015, this situation got worse, and when the federal government decided in September 2015 to open the German borders, it collapsed. During 2015, more than 900,000 asylum seekers arrived. More than 500,000 asylum seekers in 2015 could not apply for asylum, and many more were not even registered and identified. The Federal Office (BAMF) was not able to manage the flow of applications; as a consequence refugees had to wait for the decision on their application for several months and sometimes even years. The states, local governments and many volunteers worked hard and successfully to house and feed the refugees. To make up for the deficits and to demonstrate activity at the level of the federal government, it produced a multitude of laws and regulations in 2015/16, which consisted of a mix of easing previous and introducing novel restrictions, and a curtailment of some previous benefits and the introduction of some new ones along with many other changes.

According to BAMF, the numbers of unaccompanied minors increased tremendously in 2015/2016. Up to 2013 less than 2000 minors arrived per year; the numbers increased steeply from 4398 in 2014, to 22,255 in 2015 and another 35,939 in 2016. In 2017, the number of minors dropped to 4201, following an overall decrease in the number of refugees for the first 4 months of 2017. By law, every unaccompanied minor refugee has to be cared for by the local youth welfare. He/she is entitled to the same benefits as every minor under state care. According to law, a comprehensive professional clearing process has to be performed to address the social, educational, medical and psycho-social needs of each individual minor, and the community has to provide full assistance for their attainment. Thus, the social, medical as well as educational situation of unaccompanied minors is clearly better than for most minors who came with their families.

Before the increase, unaccompanied minors had been taken care of mostly in residential centers specialized in the accommodation of youths, which worked together with local youth welfare agencies. Thereafter, until the point of writing, more and more supervised flat sharing has been established; in addition, foster care has been expanded. Officials in Germany were not able to account for 9000 previously registered unaccompanied minors in August
2016; exploitation and abuse cannot be dismissed as two of several reasons for their "disappearance".

The dramatic influx of up to 20,000 refugees over a single weekend in Munich in September 2015 was managed via initial rapid medical screens for urgent health problems and contagious disease, which were to a large extent conducted by volunteer health care professionals. Mandatory full medical exams were performed subsequently as part of the asylum application to check for infectious diseases and to administer immunizations [13]. A cross-sectional survey based on 102 unaccompanied asylum-seeking adolescents aged 12-18 years in the city of Bielefeld revealed a complex disease burden with a high prevalence of infections $(58.8 ; 20 \%$ infected with parasites), mental illness $(13.7 \%)$ and iron deficiency anemia (17.6\%) and a low prevalence of non-communicable diseases $(<2.0 \%)$ [14]; West Asians had the highest prevalence of mental disorders $(20.0 \%)$.

In a Nature News Feature Abott quotes a German psychologist from Constance, according to whom one half of all refugees have a mental disorder and $25 \%$ have posttraumatic stress disorder, depression or anxiety, which would not improve without treatment. A preliminary treatment study focusing on post-traumatic stress symptoms in six severely traumatized refugees aged $\leq 18$ years suggested that trauma focused cognitive behavioral therapy is feasible in reducing symptoms [15]. The youth welfare system bears the brunt of the problems related to the large influx of young refugees. The refugees require help to learn German and the German culture, to become integrated in schools, sports clubs and other social groups, and to leave group homes to establish an independent living after becoming adults. The staff of the youth welfare system is confronted with the mental symptoms of the refugees and the problems related to uncertainties as to the status of a subgroup of the unaccompanied minor refugees (see above). From a clinical perspective, the language barrier (frequently requiring the presence of translators) represents the major problem related to the psychiatric diagnostic assessment and treatment of refugee minors with mental disorders in Germany. Accordingly, inpatient treatment is restricted to mental health emergencies only; refugees cannot adequately communicate with the hospital staff and in addition can be re-traumatized by being treated in a (locked) ward. The numbers of unaccompanied minors who are referred as outpatients are increasing; symptoms include persistent or recurrent somatic complaints such as headaches, sleep problems, depressive symptoms, post-traumatic stress symptoms and substance use disorders. More recently, children of refugee parents are also being referred to outpatient units. Many child and adolescent psychiatric departments have opened specialized outpatient units led by a physician or psychologist, who have volunteered to focus on mental health issues of refugees aged $\leq 18$; these health 
care professionals require supervision in light of the confrontation with severe traumata and different cultures.

\section{United Kingdom}

The United Kingdom (UK) is a country that has a high level of devolution and is made up of four countries: England, Scotland, Wales, and Northern Ireland. Scotland, Wales and Northern Ireland have devolved self-governments. Across the four countries of the UK, there are variations in health service systems, education, social welfare, and laws, and these include law about child welfare and child protection. However, the UK parliament in Westminster has jurisdiction over the country's borders, which includes migration policy. The UK Home Office is responsible for forming and implementing migration policy, which is applied across the four countries.

The population of the UK was 65.6 million in 2016. Immigration has been higher than emigration since the early 1990 s, and in $2015,631,500$ people came to the UK. In $2015,13.3 \%$ of the population were born abroad, the most common countries being Poland $(831,000)$, India $(795,000)$, Pakistan (503,000), and Republic of Ireland $(382,000)$. In addition, there is considerable ethnic diversity, with 6.9 and $3 \%$ of the population in the 2011 census self-identifying as being Asian or Asian British, and Black or Black British, respectively.

The UK has been a receiving country for people fleeing persecution for hundreds of years, and since the end of the second world war, there have been fluctuating numbers of asylum seekers coming to the UK. Wars and the emergence of state tyrannies that persecute their civilian populations have resulted in flows to the UK from Hungary after the events of 1956, Czechoslovakia in 1968, Chile after the 1973 Pinochet coup, dictatorship in Argentina, war in former Yugoslavia in the 1990s, and since the 1990s a continual flow from the Horn of Africa, the Middle East and Afghanistan.

Regarding the numbers of asylum seeker applications in the UK, there was a peak in 2002 with 84,132 , followed by a reduction to 17,916 in 2010 (20 years low), and a slight increase in 2016 to 30,603 (House of Commons Library, Asylum statistics, August 17, 2017). In 2015 , asylum seekers accounted for around $5.3 \%$ of the UK immigrants. The largest numbers of asylum seeker applications to the UK in the year ending March 2016 were from the following nationalities: Iran (4305), Eritrea (3321), Iraq (2805), Sudan (2769), Pakistan (2669), and Syria (2539). The UK policy had been increasingly to restrict immigration and asylum seekers entering the country. The European refugee crisis in 2015 was not followed by a very significant increase of asylum seekers arriving in the UK, unlike the situation of many European countries.

In 2016, there were 8610 applications of dependents for asylum. These were mainly young people aged 18 years and below. Since it can take years for asylum applications to be processed and final decisions made, many children who are dependents, i.e., accompanied by family will have sought asylum in previous years, but the exact figure is hard to ascertain. In 2016 3,175 unaccompanied asylumseeking children (UASC) sought asylum in the UK. This is below the peak of 4060 in 2008. The nationalities that lodged the highest number of UASC applications are: Afghan (740), Albanian (407), and Eritrean (405).

The influx of asylum seekers and refugees to the UK in the 1990s provided a stimulus for research, mainly from centers in London and the South East of England. Research topics included epidemiological studies which showed the elevated prevalence of psychiatric disorders and risk of disorder amongst recently arrived asylum seekers and refugees such as those from Kosovo [16] and Somalia [17, $18]$ and also children [19, 20]. Studies investigated service delivery for adults [21] as well as children [22] including the use of school-based services [23, 24]. Investigation has also addressed the special needs of UASC in the UK context $[25,26]$.

The UK Home Office is responsible for forming and implementing migration policy, which is applied across the four countries. The branch of the Home Office responsible for the management of adult asylum seekers, including their dependent children, is the National Asylum Support Service (NASS). This organization manages the dispersal, housing and financial support to which asylum seekers are entitled. Asylum seekers are entitled to access the National Health Service (NHS) including mental health services. Many NHS mental health providers offer specialist treatment services for psychological trauma and some also have services for refugees, which include therapists who speak many languages. Across England since 2012, there has been a relatively well-funded initiative to make available psychotherapy including CBT for PTSD for children and adults, which asylum seekers are entitled to access (https:// www.england.nhs.uk/mental-health/cyp/iapt/). There are a number of organizations outside the NHS which provide mental health services. Freedom from Torture (https:// www.freedomfromtorture.org/) provides therapy and medical evidence to support victims' asylum claims. There are centers in the main towns in England and Scotland. The Refugee Council (https://www.refugeecouncil.org.uk/) is an advocacy organization that also provides psychotherapeutic services of children and adults. 


\section{Sweden}

Sweden has a population of 10 million with a fertility rate of $1.9 \%$. Median age is 41 and $85 \%$ of the inhabitants live in urban areas. Following the Syrian popular uprisings in 2011, the subsequent civil war and the rise of the Islamic State, large numbers of refugees, mostly from Syria and Iraq, sought asylum in neighboring countries and many made their way to Europe leading to a public debate on what was termed the refugee crisis. In such a context, Swedish public discourse strongly emphasized Sweden's traditional generosity towards immigrants, and Sweden became the first country in Europe to grant permanent residency to Syrians already within its border.

The percentage population with refugee background is hard to come by because refugees are not tracked in the statistics over time. We can get annual numbers of applications and awards of residency permits, but no tracking of how many leave or change status. There are some percentages of the refugees to total immigrants (about 10-12\%) but the percentage of immigrants is itself tricky (about $12-16 \%$ depending on the source). In 2015, there were 169,520 refugees who were granted asylum in Sweden. Between 1980 and 2014, there were 477,976 who were granted asylum. The three largest groups by originating country from 2015 onwards were: Syria, Afghanistan, Iraq; and 1980-2014: Former Yugoslavia, Iraq, Iran. Between 2000 and 2016, 222,515 children sought asylum in Sweden (32\% of total asylum applications). Between 2000 and 2016, 65,649 unaccompanied minors sought asylum in Sweden (about 10\% of annual asylum applicants). Half of the unaccompanied minors come from Afghanistan, and the large majority (88\%) are boys. According to Eurostat, in 2015 the highest number of asylum applicants considered to be unaccompanied minors was registered in Sweden (with almost 35,300 unaccompanied minors, or $40 \%$ of all those registered in the EU Member States) [27].

With regards to refugees' mental health, many studies have been carried out and also some relatively rare studies that have addressed serious psychiatric disorder. It has been found that refugees are $66 \%$ more likely to develop schizophrenia and other non-affective psychoses than nonrefugee migrants from the same region of origin and 3.6 times more likely to develop these disorders compared to native born Swedes [28]. Another study finds that young adult refugees are more likely to be admitted to a psychiatric hospital for inpatient and compulsory care, but not for outpatient care (but the pattern was found to change over time whereby refugees were using more outpatient care the longer they stayed in Sweden). The same study also finds that refugees who settled in Sweden as unaccompanied minors "were more likely to be admitted to inpatient psychiatric care than teenage refugees who settled with their families" [29].

After having a relatively generous refugee reception policy, the government implemented a few changes making for a more restrictive policy environment. In addition to border controls, and ID checks between Sweden and Denmark, the government has also restricted the granting of permanent residency, family reunification, and implemented tougher maintenance requirements for family member immigration. Some categories of protection were eliminated altogether such "persons otherwise in need of protection". More precisely, on 20 July 2016, a temporary law was introduced, adapting Sweden's asylum rules to the minimum levels under EU law. Under the temporary law, refugees and persons eligible for subsidiary protection (quota refugees excepted), are granted temporary residence permits and the opportunities for family reunification have been limited. The restricted access to being granted a residence permit in Sweden is considered necessary to maintain for a period of at most 3 years. There has also been a discussion about introducing medical age determination of asylum seekers.

Currently several governmental bodies are taking the leading in accommodating refugees' needs in Sweden:

- The Migration Board, which processes cases, provides housing for asylum seekers and handles the resettlement process for quota refugees.

- Public Service Employment Service: Assists in the settlement process of refugees, coordinates introduction program (language and culture classes), job training and employment validation, provides introduction guides (who provide advice), and manages benefits to refugees attending the introduction program.

- Municipalities: in charge of housing of refugees with residence permits, assistance at arrival for quota refugees, offers Swedish for Immigrants classes, and provides cultural orientation programs.

\section{Norway}

On 1st January 2017, the population in Norway was $5,258,317$ inhabitants, with $4 \%$ of Norwegian population from a refugee background. According to the Norwegian Directorate of Immigration (Utledningsdirektorate, UDI), 199,400 persons with a refugee background were living legally in Norway by 1st January 2016; this amounts to 3.8\% of the total population. Refugees come from a total of 169 different countries, mostly from Somalia, Iraq, and Eritrea (29\% of the total number of immigrants).

Over the last few years, the number of asylum applications to Norway has been relatively stable. In 2012 the total number was 9785 . The following 2 years' numbers fluctuated 
between 11,000 and 12,000. However, when looking at the period 2014-2015, the number of asylum seekers to Norway increased considerably, and 2015 saw a threefold increase in asylum seekers. According to the UDI, more than 31,000 people applied for asylum in Norway in 2015. In total, more than half of the asylum seekers to Norway in 2015 were from Syria. Nonetheless, following this sharp rise in the number of asylum seekers, the number of new asylum seekers has seen a sharp drop, from a record 25001 week in midNovember 2015-363 and 285 in the first and second weeks of December 2015. Eritreans were most likely to be allowed to remain in Norway, which represents $90 \%$ of all applications processed in 2015. Among Syrians, 70\% were allowed to stay, while $30 \%$ of the applications were referred to other countries or withdrawn. $44 \%$ of the Afghan applicants were granted asylum here, but only $8 \%$ of Iraqis. Applications from countries such as Kosovo, Albania, Ukraine, Morocco, Egypt and Bangladesh, were mainly unsuccessful so permission to stay was withheld, and similarly few of the applicants from Lebanon, Nigerian and Pakistan were successful.

The number of asylum coming to Norway has reduced since the start of 2016, with only 2,804 asylum seekers registered by the end of January 2016. The main reason for this was a proposal from the parliament to tighten the asylum policy, accompanied by stricter border checks (Regjeringen. no, 2015). The justification for these measures was the need for quick and effective integration, and it included reduced benefits for people living in reception centers, fewer temporary residence permits, rapid return should the situation in the country of origin improve, and limited family reunification and family establishment rights for refugees. By the end of August 2016, a total of 2248 asylum seekers had been registered in Norway, a decrease of $73 \%$ compared with the previous year. The number of people seeking asylum in Norway has not been so low since 1997.

Despite the restrictive measures implemented by the government, the Norwegian people are welcoming towards refugees: in a recent study conducted to evaluate attitudes towards immigration, participants were asked whether it should be more easy or more difficult for immigrants to obtain permission to stay in Norway, and almost $50 \%$ answered that it should be the same as it has long been, with no new restrictions, $12 \%$ wanted more liberal access to residence permits, while $33 \%$ wanted more restrictions [30].

The government has implemented several measures with the aim of providing immigrants with equitable health services. Because of the high immigration to Norway over the last decade, the Ministry of Health and Care Services prepared a strategy for immigrant health for the period 2013-2017, which included three main objectives:

- health professionals at all levels should have knowledge about the distribution of the various immigrant groups and the cultural challenges associated with ensuring immigrants obtain equal health and care services;

- healthcare staff at all levels should facilitate good communication with patients with different linguistic backgrounds (for example, interpretation needs and the use of qualified interpreters);

- the health and care services should have access to up-todate information regarding immigrant health and their use of healthcare, and they should use this knowledge in the development of services.

There are several organizations in Norway involved in the mental health care of refugees and among the biggest are the Regional centers on violence, traumatic stress and suicide prevention (RVTS), the Norwegian Centre for Minority Health Research (NAKMI) and the Norwegian Centre for Violence and Traumatic Stress Studies (NKVTS).

There are RVTS centers in each of the five regions of Norway. Their main purpose is to support the health services with expertise on trauma and traumatic stress (including psychosocial preparedness), violence and abuse (including domestic violence), the prevention of suicide and self-harm, refugee health, and forced migration. The RVTS strive to be easily accessible to the employees in the municipal and the specialized health services, as well as to voluntary organizations. They contribute to competence-raising through education, guidance and networking across sectors, agencies, and management levels. The centers also provide consultation for professionals from the health area on topics related to psychosocial problems with refugees and asylum seekers, as well as suggesting ways of working with refugees and asylum seekers in the health region.

The NAKMI is a national research, development and policy center, and it works towards the provision of equity in health care for immigrants and their children in Norway. The goal is to create and disseminate research-based knowledge that promotes good health and equal health care for people with immigrant backgrounds. The primary target groups are decision-makers, healthcare professionals, researchers, and students. The NAKMI's core activities are research, development and dissemination work (including training, guidance, and counseling). It is a driving force for the production and dissemination of knowledge about immigrant health, with particular emphasis on the largest immigrant groups and the most widespread health challenges they face. The center strives for practicality and collaboration with clinicians, but does not have its own clinical activities.

The NKVTS develops and disseminates knowledge and competence in the field of violence and traumatic stress. The centre's objective is to help prevent and reduce the healthrelated and social consequences that can follow from exposure to violence and traumatic stress. The centre has an international outlook and develops knowledge at an international 
academic level. The centre assumes an interdisciplinary perspective, which includes medical, psychological, social, cultural and legal aspects. Among the main topics of research are violence, sexual abuse, disasters, and refugees/asylum seekers. It disseminates the results of research in the form of teaching, guidance and counseling, in cooperation with other research institutions and professional agencies in the field of violence and trauma.

As regards mental health among refugees, they demonstrate considerably higher levels of psychiatric disorders $[31,32]$. However, there is insufficient research on refuges health issues in Norway. Overall knowledge of refugees' mental health at arrival in the host country is limited to those who arrived before the new immigrant wave in 2015. Existing research on asylum seekers and mental health confirms results from international studies that asylum seekers face health-related problems that are different from those of the rest of the population [33, 34]. Several clinical $[35,36]$ and community studies [37-39] reported higher rates of post-traumatic stress disorder (PTSD) and emotional symptoms, mental distress, and conduct problems among refugees than among ethnic Norwegians [40].

Most in need are unaccompanied refugee minors (UM) with 10,535 UM applied for asylum in Norway in 2015. This is the highest number ever [30]. By 2015, the number of asylum-seeking children was so high that it was about the same level as the total number of asylum seekers the year before. By 2016, 1221 asylum-seeking children arrived, a fall of almost $90 \%$ compared to 2015. More than half of the children who applied for asylum in 2015 reported that they were single minors. By 2016, the percentage arriving as single minors fell to less than $30 \%$, and children from Syria formed the largest group.

Studies in Norway with unaccompanied minors confirms the findings from other countries that they are at high psychiatric risk. Unaccompanied refugee minors consistently reported significantly higher levels of internalizing problems, traumatic stress, and stressful life events [41]. In a study by Jakobsen et al. [42], 41.9\% of the participants among unaccompanied minors fulfilled diagnostic criteria for a current psychiatric disorder. It was established that among the commonest disorders amongst unaccompanied children were PTSD (30.6\%), depression (MDD) (9.4\%), agoraphobia (4.4\%) and anxiety (3.8\%), and they reported a high level of past physical abuse (78\%). In another study of unaccompanied minors it was found that there was no improvement in their mental health at 2 years follow up [43].

\section{Final comments}

Europe has had a long history of producing and receiving refugees. At the end of the twentieth century, the collapse into civil war of Yugoslavia resulted in hundreds of thousands of displaced and refugee people. However, the increase in war in the Middle East and ongoing conflict in Afghanistan resulted in a massive refugee influx which peaked in 2015. Their arrival coincided with ongoing austerity and economic policies that restricted public expenditure. The refugee crisis has put pressure on many services. This has resulted in public concern about the refugee numbers and many European countries have revised their immigration policies and practices. It is known that refugees are at high risk of mental health problems, many of which arise as a consequence of their living conditions in the hosting countries. Far more work is needed to establish the best health care systems, although given the varied health service delivery systems across Europe standardization may not be feasible. Child refugees and unaccompanied minors are very sizable vulnerable groups which require far greater attention in terms of service provision and also investigation to identify the most effective treatment models. Although this requires resourcing, it is expected that over time the improved mental health and effective social integration of refugees will result in huge benefits for the refugees themselves and also the host communities [44].

The attitudes of the national hosting populations obviously play a major role for the acculturation process of migrants and refugees and thus presumably also for their mental health. There are substantial differences between European countries; this range extends from very restrictive policies that have served to keep influx stable throughout the period of turmoil in Syria, Iraq, Afghanistan and other parts of the world. On the other hand, segments of the populations of some countries have welcomed the influx with many citizens personally actively engaged in the provision of substantial support to the refugees. These differences are posing a political threat to the unity of Europe, but have also entailed substantial friction within some countries, in which attitudes range from outright hostility and even attacks towards immigrants and refugees to a culture of welcoming ("Willkommenskultur"). The radicalization of a small number of mostly young immigrants and refugees throughout Europe poses additional dangers. It is, thus, all the more important that we as child and adolescent psychiatrists attempt to treat as best as possible the children and adolescents who are brought to our attention. We also need to make sure that the responsible local and national authorities understand the importance of the environment of the hosting country with respect to the mental health of young immigrants and refugees.

There is a need for research programs in a national and European level, concerning critical issues related to mental health of refugee families such as resilience factors that are associated with levels of psychological well-being. Additionally, a specific focus should be given in highly sensitive public issues such as the risk of discrimination and 
maladaptive acculturation. Given that the existing knowledge is related to various refugee populations, cultures and policies in each host country as well as to different refugee background (i.e., socioeconomic characteristics) and different periods of immigration, a network should be developed in order for the European countries to promote and facilitate research focusing on the needs of the current "wave" of refugees aiming to support and disseminate intervention programs as well as preventive actions for refugee families raising infants children and adolescents. In this direction, the role of academic institutions of child and adolescent psychiatry such as ESCAP and European Universities is crucial.

\section{References}

1. Hebebrand J, Anagnostopoulos D, Eliez S, Linse H, Pejovic-Milovancevic M, Klasen H (2016) Arriving in Europe: what mental health professionals need to know. Eur Child Adolesc Psychiatry 25(1):1-6

2. Anagnostopoulos DC, Heberbrand J, Eliez S, Doyle MB, Klasen H, Crommen S, Cuhadaroğlu FC, Pejovic-Milovancevic M, Herreros O, Minderaa R, Karwautz A, Svedin CG, Raynaud JP (2016) European Society of Child and Adolescent Psychiatry: position statement on mental health of child and adolescent refugees. Eur Child Adolesc Psychiatry 25(7):673-676

3. Nasıroğlu S, Çeri V (2016) Posttraumatic stress and depression in Yazidi refugees. Neuropsychiatr Dis Treat 12:2941-2948

4. Çeri V, Özlü-Erkilic Z, Özer Ü, Yalcin M, Popow C, AkkayaKalayci T (2016) Psychiatric symptoms and disorders among Yazidi children and adolescents immediately after forced migration following ISIS attacks. Neuropsychiatr 30:145-150

5. Hughes P, Hijazi Z, Saeed K (2016) Improving access to mental healthcare for displaced Syrians: case studies from Syria, Iraq and Turkey. BJPsych Int 13:84-86

6. Karadag M, Gokcen C, Dandil F, Calisgan B (2017) Our experience with Syrian refugee patients at the child and adolescent psychiatry clinic in Gaziantep, Turkey. Int J Psychiatry Clin Pract $12: 1-3$

7. Anagnostopoulos D, Soumaki E (2013) The state of child and adolescent psychiatry in Greece during the international financial crisis: a brief report. Eur Child Adolesc Psychiatry 22:131

8. The Huffington Post (2015). Available at: http://www.huffingtonpost.gr/2015/12/25/metanasteutiko-ellada-_n_8875108.html

9. Ministry of Migration Policy (2017). Available at: http://asylo.gov.gr/wp-content/uploads/2017/07/ Greek_Asylum_Service_Statistical_Data_GR.pdf

10. E.K.K.A. National Center for Social Solidarity. Situation update: unaccompanied children in Greece. Available at: http://www.ekka. org.gr/files/EKKA\%20dashboard\%2030-9-2017.pdf

11. Anagnostopoulos D, Vlassopoulou M, Rotsika V, Pehlivanidou H, Legaki L, Rogakou E, Lazaratou H (2004) Psychopathology and mental health service utilization by immigrants' children and their families. Transcult Psychiatry 41:465-486

12. Triantafyllou K, Othiti I, Xylouris G, Moulla V, Ntre V, Kovani P, Gertsou I, Anagnostopoulos D (under review) Mental health and psychosocial factors in youth refugees, immigrants and Greeks: A retrospective study. Psychiatriki

13. Nicolai T, Fuchs O, von Mutius E (2015) Caring for the Wave of Refugees in Munich. N Engl J Med 373(17):1593-1595

14. Marquardt L, Krämer A, Fischer F, Prüfer-Krämer L (2016) Health status and disease burden of unaccompanied asylum-seeking adolescents in Bielefeld, Germany: cross-sectional pilot study. Trop Med Int Health 21(2):210-218

15. Unterhitzenberger J, Eberle-Sejari R, Rassenhofer M, Sukale T, Rosner R, Goldbeck L (2015) Trauma-focused cognitive behavioral therapy with unaccompanied refugee minors: a case series. BMC Psychiatry 15:260

16. Turner SW, Bowie C, Dunn G, Shapo L, Yule W (2003) Mental health of Kosovan Albanian refugees in the UK. Br J Psychiatry 182:444-448

17. Bhui K, Abdi A, Abdi M, Pereira S, Dualeh M, Robertson D, Sathyamoorthy G, Ismail H (2003) Traumatic events, migration characteristics and psychiatric symptoms among Somali refugees-preliminary communication. Soc Psychiatry Psychiatr Epidemiol 38:35-43

18. Bhui K, Craig T, Mohamud S, Warfa N, Stansfeld SA, Thornicroft G, Curtis MC, Crone P (2006) Mental disorders among Somali refugees: developing culturally appropriate measures and assessing socio-cultural risk factors. Soc Psychiatry Psychiatr Epidemiol 41:400-408

19. Fazel M, Stein A (2003) Mental health of refugee children: comparative study. BMJ 327:134

20. Bronstein I, Montgomery P, Dobrowolski S (2012) PTSD in asylum-seeking male adolescents from Afghanistan. J Trauma Stress 25:551-557

21. McCrone P, Bhui K, Craig T, Mohamud S, Warfa N, Stansfeld SA, Thornicroft G, Curtis S (2005) Mental health needs, service use and costs among Somali refugees in the UK. Acta Psychiatr Scand 111:351-357

22. Howard M, Hodes M (2000) Psychopathology, adversity, and service utilization of young refugees. J Am Acad Child Adolesc Psychiatry 39:368-377

23. Fazel M, Garcia J, Stein A (2016) The right location? Experiences of refugee adolescents seen by school-based mental health services. Clin Child Psychol Psychiatry 21:368-380

24. Dura-Vila G, Klasen H, Makatini Z, Rahimi Z, Hodes M (2013) Mental health problems of young refugees: duration of settlement, risk factors and community-based interventions. Clin Child Psychol Psychiatry 18:604-623

25. Hodes M, Jagdev D, Chandra N, Cunniff A (2008) Risk and resilience for psychological distress amongst unaccompanied asylum seeking adolescents. J Child Psychol Psychiatry 49:723-732

26. Sanchez-Cao E, Kramer T, Hodes M (2013) Psychological distress and mental health service contact of unaccompanied asylum-seeking children. Child Care Health Dev 39:651-659

27. Eurostat (2016) Available at: http://ec.europa.eu/eurostat/ documents/2995521/7244677/3-02052016-AP-EN.pdf/

28. Hollander A-C et al (2016) Refugee migration and risk of schizophrenia and other non-affective psychoses: cohort study of 1.3 million people in Sweden. BMJ 352:1030

29. Manhica H, Almquist Y, Rostila M, Hjern A (2016) The use of psychiatric services by young adults who came to Sweden as teenage refugees: a national cohort study. Epidemiol Psychiatr Sci 1:9

30. Statistics Norway (2016) Attitudes towards immigrants and immigration. Statistics Norway, Oslo. https:// www.ssb.no/en/befolkning/artikler-og-publikasjoner/ more-immigrant-friendly-attitudes

31. Hubbard J, Realmuto G, Northwood A, Masten A (1995) Comorbidity of psychiatric diagnoses with posttraumatic stress disorder in survivors of childhood trauma. J Am Acad Child Adolesc Psychiatry 34:1167-1173

32. Sack W, McSharry S, Clarke G, Kinney R, Seeley J, Lewinsohn P (1994) The Khmer Adolescent Project. Epidemiologic findings in two generations of Cambodian refugees. J Nerv Ment Dis 182:387-395 
33. Berg JE (2009) The level of non-Western immigrants' use of acute psychiatric care compared with ethnic Norwegians over an 8-year period. Nord J Psychiatry 63(3):217-222

34. Neumayer S, Skreslett A, Borchgrevink M, Gravråkmo S et al (2006) Psykososialt arbeid med flyktningbarn. Introduksjon og fagveileder. NKVTS, Oslo

35. Larsen L, Skreslett A (2002) En kartlegging av sykdomsforekomster hos flyktninger ved Flyktningehelseteamet $\mathrm{i}$ Trondheim. Linjer fra Psykososialt senter for flyktninger 12(2):21-26

36. Lavik NJ, Solberg Ø, Varvin S (1997) Psykisk helse blant flyktninger. Tidsskrift for Norsk Lægeforening 117:3654-3658

37. Lie B (2003) The triple burden of trauma, uprooting and settlement. A non-clinical longitudinal study of health and psychosocial functioning of refugees in Norway. Dissertation, University of Oslo

38. Lie B, Lavik NJ, Laake P (2001) Traumatic events and psychological symptoms in a non-clinical refugee population in Norway. $\mathrm{J}$ Refug Stud 14(3):276-294

39. Vervliet M, Meyer Demott MA, Jakobsen M, Broekaert E, Heir T, Derluyn I (2014) The mental health of unaccompanied refugee minors on arrival in the host country. Scand J Psychol 55(1):33-37
40. Sagatun A, Lien L, Søgaard AJ, Bjertness E, Heyerdahl S (2008) Ethnic Norwegian and ethnic minority adolescents in Oslo, Norway. A longitudinal study comparing changes in mental health. Soc Psychiatry Psychiatr Epidemiol 43(2):87-95

41. Jensen K, Skårdalsmo E, Fjermestad K (2014) Development of mental health problems - a follow-up study of unaccompanied refugee minors. Child Adolesc Psychiatry Ment Health 20148:29

42. Jakobsen M, Demott M, Heir T (2014) Prevalence of psychiatric disorders among unaccompanied asylum-seeking adolescents in Norway. Clin Pract Epidemiol Ment Health 10:53-58

43. Seglem KB, Oppedal B, Raeder S (2011) Predictors of depressive symptoms among resettled unaccompanied refugee minors. Scand J Psychol 52(5):457-464

44. Goldin I, Cameron G, Balarajan M (2011) Exceptional people. How migration shaped our world and will define our future. Princeton University Press, Princeton 